THE CONJOIN SEQUENCE DIAGRAM: A METHOD OF DESCRIBING CONJOIN SETS

\title{
PETER HISCOCK
}

Anthropology of sociology University of Queengland

\section{INTRODUCTION}

Conjoin analysis involves physically fitting back together objects broken in antiquity. objects which are refitted are said to be 'conjoined', and a number conjoined together are called a 'conjoin set'. Conjoin analyses of stone artefacts began over a century ago with the work of Spurrell (1880; 1884). Subsequently, this approach has been used for a number of purposes. Cahen and colleagues used the vertical separation of conjoined artefacts to measure the extent of post-depositional displacement at old world sites (Cahen. 1978; Cahen and Moyersons 1977; Cahen et al 1979; Van Noten et al 1980). A number of researchers have used conjoin data to discuss the horizontal movement of humans and their debris across living floors (eg. Leroi-Gourhan and Brezillon 1966, 1972; Frison 1968, 1974; Van Noten, et al 1980; Singer 1984). Discussions of artefact breakage have often been accompanied by drawings of refitted fragments (eg. Lenoir 1975; Mallouf 1982). By providing information about sequential blows applied to a core, conjoin analysis has also aided in the reconstruction of the knapping process (eg. Kobayashi 1970; Frison 1974; Van Noten 1975; Fasham and Ross 1978; Leach 1984). In Australia, conjoin analysis has been used to examine vertical displacement (eg. Stern 1980) and to assist reconstruction of prehistoric stoneworking technology (eg. Noetling 1908; Luebbers 1978; Witter 1977).

One limitation to the use of conjoin analysis has been the inability to concisely describe conjoined artefacts and their interrelationships other than by lengthy discussion and costly drawings and/or photographs. Further, it is impractical to describe threedimensional relationships for all artefacts in a large conjoin set using such methods. Since conjoin analysis is currently a major tool in the reconstruction of prehistoric knapping behaviour, the development of a simple notational system with which to describe conjoin relationships is clearly needed. This paper offers one such descriptive system - the conjoin sequence diagram. 
The conjoin sequence method, with minor modification, is based upon the Harris stratigraphic Matrix (Harris 1979). Here the basic unit of interest is the conjoin set, comprising all artefacts within an individual reduction sequence which may be refitted. Although an entire reduction sequence may occasionally be reconstructed, more often the conjoin set will represent only one portion of it.

The logic of the conjoin sequence diagram is simple enough. Each flake is listed in order of its removal from the core. The list takes the form of a column, with the first flake struck being placed at the top. The core itself is placed at the bottom of the list. A branch is developed whenever a flake is retouched, and all flakes struck from a retouched flake are"listed in such a branch (see Figure 1). Complexity is introduced by factors such as missing and broken flakes, each of which are indicated in a particular fashion. The rules for constructing a conjoin sequence are summarized below.

1. Each separate object is represented by a box, within which is placed an object identifier such as site name, square number, spit number, artefact number, etc. (Figure 1).

2. Within any one branch of the sequence all objects on the same row represent a single blow. When there are two or more objects in one row they are either fragments of a broken flake or different products of the same blow (such as a flake and an eraillure flake). Proximal fragments are placed to the left of the row, and distal fragments to the right.

3. The vertical order of artefacts follows strictly the order of objects produced in the knapping sequence. In any conjoin set the first flake removedis placed at the top of the páge and each successive flake is placed in turn below this until the final flake in the conjoin set is reached. If the sequence branches, the position of flakes within one branch continues to be sequential. There is no sequential relationship between artefacts in different branches (Figure 1 and point 7 below).

4. Where two flakes cannot be ordered relative to one another (eg. Figure 2, artefacts 21 and 22), but can be placed below and above surrounding flakes in the sequence (Figure 2, artefacts 20 and 23), they should be vertically separated on different paths within one branch. It is then clear that they are not contemporary events, and that their order relative to one another is unknown. The choice as to which to place above the other is subjective but I suggest they be ordered according to their assumed position in the sequence (no confusion can arise concerning the fact that the order is an inference).

5. An asterisk indicates than an object produced by a knapping action is missing from the conjoin set (Figures 1,2 , and 3 ).

6. Missing-portions of an object, such as the distal end of a broken flake or an eraillure flake, may be shown by a question mark (Figure 3 ).

7. Flake retouch can be illustrated by initiating a branch to the right of the box representing the retouched artefact (Figure 1, artefact 2). Thus, a retouched flake remains in the correct position in the original sequence but all flakes removed from it form a new branch. This 
branching may occur any number of times. objects on different branches may not be considered contemporary.

8. Solid vertical lines connecting artefacts indicates their physical connection in the conjoin analysis. Broken vertical lines indicate an inferred connection only.

9. Solid "equals" signs $(====)$ connecting objects in the same row, such as proximal and distal fragments of a flake, indicate that they have been refitted. Broken ones $(==)$ ) indicate that the relationghip is inferred and not physical (Figure 3 ).

10. On particularly complex conjoin sets, especially those with large numbers of broken fragments, or where it is not possible to allocate artefact identifiers sequentially, it is often necessary to number each of the knapping events depicted on the conjoin sequence diagram (Figure 3). This sequence number, placed down the left hand side of the diagram, provides a more convenient reference for each knapping event than would a string of numbers. For example, in Figure 3 the second blow can be referred to as sequence number 2 rather than referring to fragments $2 \mathrm{C}-$ $1,2 \mathrm{C} / 1-2$ and $2 \mathrm{~A}-1$.

11. Additional information can be noted in columns to the right of the diagram. Any information may be listed but it is probably not practical to have more than a small number of variables (see Figures 3 and 4 ). A description of the artefact/implement type is often useful, as is an indication of the direction of the blow. The latter is simply represented by an arrow enclosed in a circle, referring to the direction of that blow in respect of a set point. Other information relevant to the reduction, such as the point of heat treatment or the occurrence of usewear, may also be noted. For example, a wavy line drawn horizontally at the appropriate point indicates the rotation of the core and the removal of small faceting flakes (1-4 mm long) from the platform (Figure 4). such faceting flakes would not usually be recovered or refitted.

\section{USES OF THE CONJOIN SEQUENCE DIAGRAM}

The presentation of conjoin sequence diagrams can be advantageous in both description and analysis of data concerning individual reduction sequences. In laboratory situations were artefacts are not glued together it provides a handy reference for their order in the conjoin set. These diagrams are particularly useful when working on museum collections where conjoined artefacts may reside in different boxes and where new numbers may not be permitted on the artefacts. A conjoin sequence diagram efficiently displays basic data about conjoin sets including object identifiers, the relationship of objects to one another, a sequence number and any other information considered relevant. It also presents other information such as length of the conjoin set, degree of artefact breakage, number and sequential position of missing artefacts, number of inferential rather than physical conjoins, sequential position of flakes selected for retouching, and so on. Finally, with a conjoin sequence diagram available as a reference map for the conjoin set, it is much easier to present analyses of sequential changes in attribute states throughout the set. 


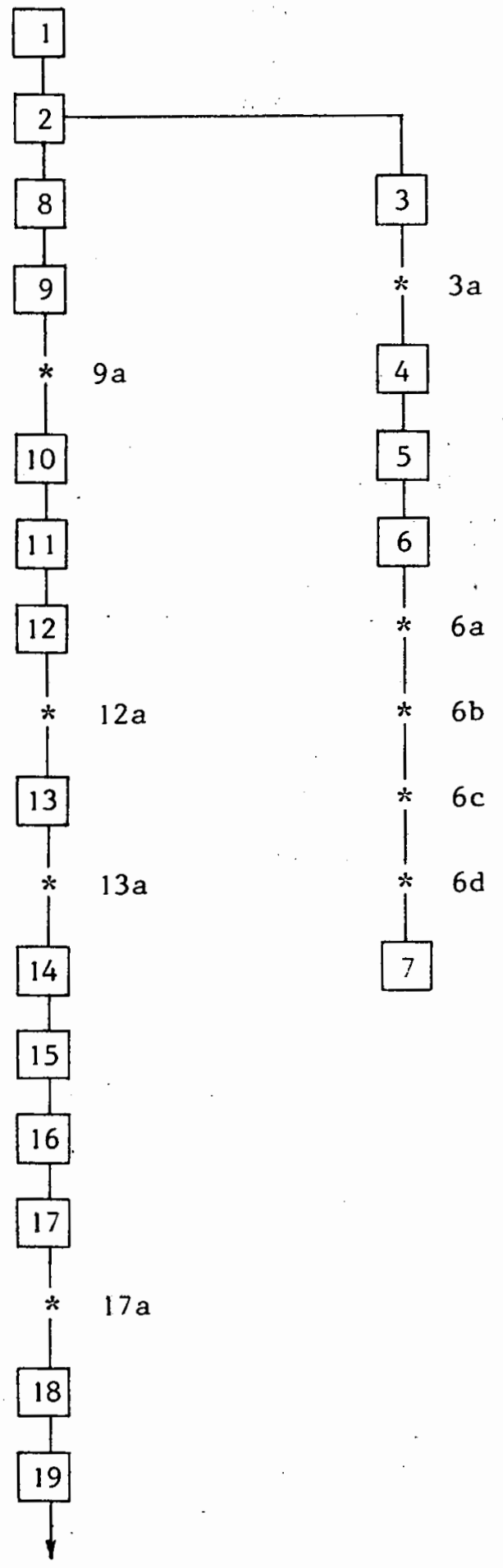

Figure 1. One portion of a conjoin sequence of conjoin set KF1-A from site H43/1, Lawn Hill, NW Queensland. 


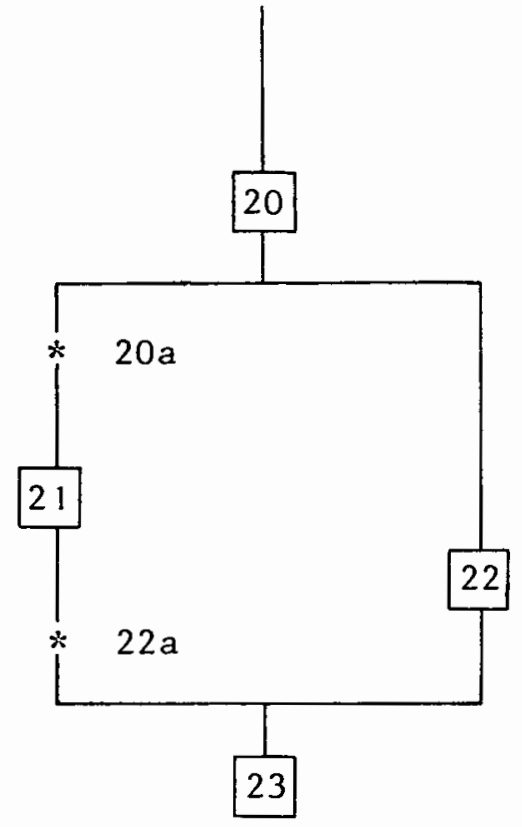

Figure 2. One portion of a conjoin sequence of conjoin set KF1-A from site $H 43 / 1$ at Lawn Hill, NW Queensland.

Sequence Number

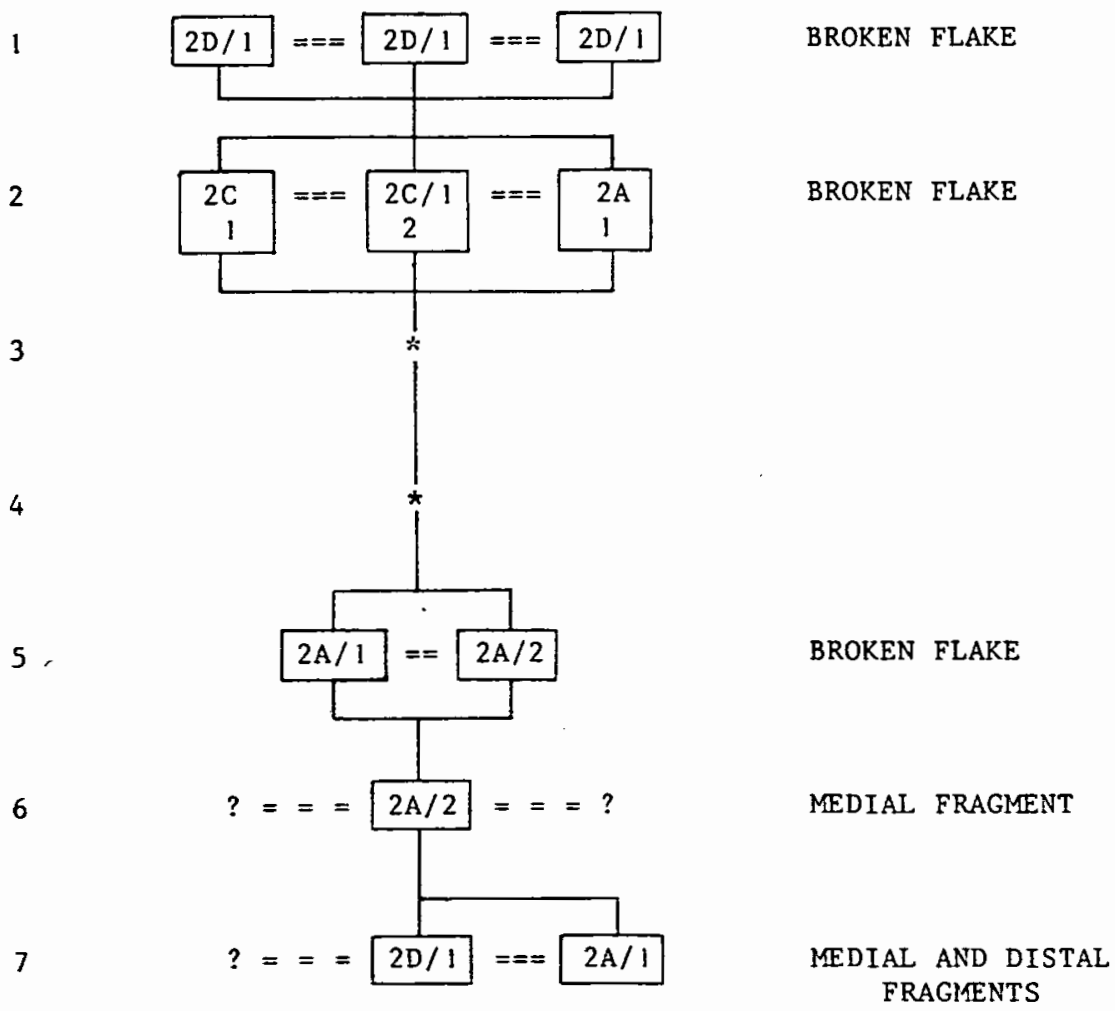

Figure 3. A conjoin sequence of conjoin set G, site RBC5, Hunter Valley, Nsw. 


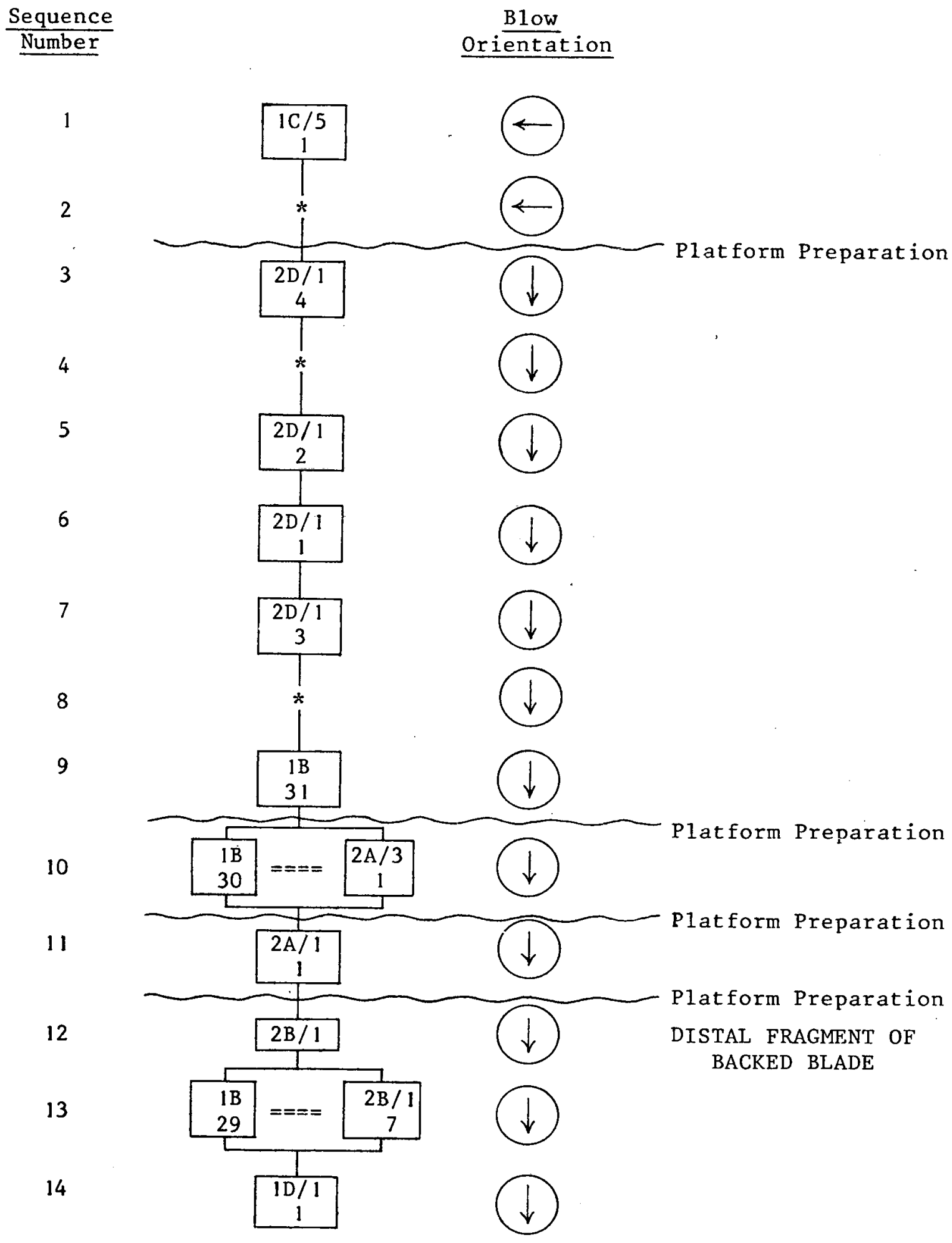

Figure 4. A conjoin sequence of conjoin set A, site RBC5, Hunter Valley, NSW. 
REFERENCES CITED

Cahen, D. 1978 New excavations at Gombe (ex Kalinga Point), Kinsasha, Zaire. Antiquity 52:51-56

Cahen, D. and J. Moyersons 1977 subsurface movements of stone artefacts and their implications for the prehistory of central Africa. Nature 266:812-5

Cahen, D., L.H.Keeley, and F.L.Van Noten 1979 stone tools, Tool kits, and Human behaviour in Prehistory. Current Anthropology 20:661-83

Fasham, P.J., and J.M.Ross 1978 A Bronze Age flint industry from a barrow site in Micheldever Wood, Hampshire. Proceedings of the Prehistoric Society 44:47-67

Frison, G.C. 1968 A functional analysis of certain chipped stone tools. American Antiquity 33(2):149-155

Frison, G.C. 1974 The Casper site: A Hell's Gap bison kill on the high plains, University of Wyoming Press.

Harris, E.C. 1979 Principles of archaeological stratigraphy. New York: Academic Press.

Kobayashi, T. 1970 Microblade Indugtries in the Japanese Archipelago. Arctic Anthropology $7(2): 38-58$

Leach, H.M. 1984 Jigsaw: recongtructive lithic technology. In J.E. Ericson and B.A. Purdy,(eds.), Prehistoric Quarries and Lithic Production, pp. 107-118. Cambridge University Press.

Leroi-Gourhan, A., and M. Brezillon 1966 L'habitation Magdalenien No.1 de Pincevent pres Montereau (Seine-et-Marne). Gallia Prehistoire $9: 263-71$

Leroi-Gourhan, A., and M. Brezillon 1972 Fouilles de Pincevent: Esgai d'analyse ethnographique d'un habitat Magdalenien (la section 36), Galia Prehistoire 7th supplement.

Lenoir, M. 1975 Remarks on Fragments with Languette Fractures. In E. Swangon (ed.), Lithic Technology: making and using stone toola, pp.129-132. The Haig: Mouton Press.

Luebbers, R.A. 1978 Meals and Menus: A study of change in prehistoric coastal settlements in South Australia. Unpublished PhD thesis, Australian National University.

Noetling, F. 1908 Notes on a chipped boulder found near Kempton, Papers and Proceedings of the Royal Society of Tasmania, 1-9

Singer, C.A. 1984 The 63-kilometre fit. In J.E. Ericson and B.A. Purdy (eds.), Prehistoric quarries and lithic production, pp.35-48. Cambridge University Press.

Spurrel1, F.C.J. 1880 on implements and chips from the floor of a Palaeolithic workshop. Archaeological Journal 37:294-9 
Spurrell, F.C.J. 1884 on some palaeolithic knapping tools and modes of using them. Journal of the Royal Anthropological Institute 13:109-118

stern, N. 1980 Taphonomy: some observations about its place in archaeology, BA (Hons) thesis, University of Sydney.

Van Noten, F.* 1975 Comment. Current Anthropology 16(3):386

Van Noten, F., D.Cahen, and L.Keeley 1980 A Paleolithic campsite in Belgium. Scientific American 242(4):44-51

Witter, D.C. 1977 The archaeology of the Discovery Bay area. Paper presented at the 1977 Anzaas conference, Melbourne. 